\title{
Rifaximin plus cefotaxime versus cefotaxime alone in treatment of spontaneous bacterial peritonitis in patients with cirrhosis

\author{
Asmaa N. Mohammad ${ }^{\mathrm{a}}$, Mahmoud K. Elsamman ${ }^{\mathrm{d}}$, Amr M. Zaghloul ${ }^{\mathrm{a}}$, \\ Hameda H. Mohamed ${ }^{\text {, }}$, Walaa I. Mohammed ${ }^{\mathrm{b}}$
}

Departments of ${ }^{\mathrm{T}}$ Tropical Medicine and Gastroenterology, ${ }^{\mathrm{b}}$ Pharmacology, ${ }^{\mathrm{C}}$ Medical

Microbiology and Immunology,

${ }^{d}$ Gastroenterology Division, Department of Internal Medicine, Sohag Faculty of Medicine,

Sohag University, Sohag, Egypt

Correspondence to Asmaa N. Mohammad, MD, Assistant Professor, 17 Abd El-Latif Abo Heggy Street, Sohag City, Sohag, 82515 Egypt. Tel: +20 1003396041 ;

fax: +20 934602963

e-mail: asmaanaser25@yahoo.co.uk

Received 29 March 2018

Accepted 16 April 2018

The Egyptian Journal of Internal Medicine 2018, 30:154-159

\begin{abstract}
Background/purpose of the study
Spontaneous bacterial peritonitis (SBP) is a cause of significantly higher morbidity and mortality in patients with cirrhosis. This study was conducted to assess the effect of adding rifaximin to cefotaxime in treatment of SBP.

Materials and methods

The study was a prospective one that involved 98 patients with cirrhosis with SBP, who were divided randomly into two equal groups. Patients in group I received cefotaxime, whereas patients in group II received a combination of cefotaxime and rifaximin. Patients were evaluated clinically, and diagnostic aspiration was repeated on the third day of antibiotic therapy.

\section{Results}

Both groups showed significant reduction in white blood cells on the third day compared with the first day $(P<0.0001)$. Polymorphonuclear leukocyte count in ascetic fluid in both groups showed significant reduction on the third day compared with the first day, and the reduction was statistically significant in group II compared with group I $(P<0.0001)$. One the third day of therapy, serum creatinine levels in group I and group II were $1.61 \pm 0.19$ and $1.28 \pm 0.37$, respectively. Both groups showed significant decrease in serum creatinine level. The reduction in group II compared with group I was statistically significant, with $P$ value less than 0.0001 . Conclusion

Rifaximin plus cefotaxime showed some favorable effects in treatment of SBP than cefotaxime alone. However, the clinical effects of these effects need to be clarified in further studies.
\end{abstract}

\section{Keywords:}

cefotaxime, liver cirrhosis, rifaximin, spontaneous bacterial peritonitis

Egypt J Intern Med 30:154-159

(c) 2018 The Egyptian Journal of Internal Medicine

1110-7782

\section{Introduction}

Spontaneous bacterial peritonitis (SBP) is a serious infection caused by bacteria in patients with cirrhosis and is associated with significant high mortality [1]. There are various clinical local and/or systemic signs for SBP, ranging from local abdominal features of peritoneal inflammation with or without manifestations of systemic inflammation (hypothermia or hyperthermia, tachycardia, tachypnea, change white blood cell count, and/or shock) to impaired renal function without explanation [2].

Small intestinal bacterial overgrowth has a significant role in the evolvement of SBP. Dysmotility of the small intestinal and bacterial overgrowth are frequent findings in hepatic patients with advanced liver cell failure and mostly contribute to increase in the number of enteric microorganisms reaching to the systemic circulation translocated from the intestinal wall $[3,4]$. Patients with cirrhosis showed increased access of intestinal bacteria to the portal circulation and these translocated bacteria and resultant cytokines are less likely to be cleared by the liver because of impaired phagocytic function of reticuloendothelial cells and increased collateral blood flow. Patients with liver cirrhosis also have immunodeficiency [5], with impaired ability to clear the translocated bacteria.

Cefotaxime, a third-generation cephalosporin, was considered to be the drug of choice in treatment of $\mathrm{SBP}$ with a dose of $4 \mathrm{~g} /$ day for at least 5 days; this dose achieves high ascitic fluid concentrations and covers most of the causative organisms [6]. Intestinal decontamination can also be achieved by norfloxacin which is used widely for prophylaxis of SBP, and this extensive long-term use leads to increased incidence of quinolone resistance and emergence of SBP caused by gram-positive organisms [7].

This is an open access journal, and articles are distributed under the terms of the Creative Commons Attribution-NonCommercial-ShareAlike 4.0 License, which allows others to remix, tweak, and build upon the work non-commercially, as long as appropriate credit is given and the new creations are licensed under the identical terms. 
Compared with norfloxacin and other antibiotics, rifaximin is virtually unabsorbable, with minimal antimicrobial resistance and high safety profile in all patient populations [8]. If rifaximin-resistant fecal strains are observed, they disappear rapidly after stopping the antibiotic treatment [9]. Rifaximinresistant organisms were reported to be weak with lower viability [10]. Moreover, rifaximin can promote the growth of beneficial gut bacteria; it actually does not change the overall composition of the gut flora, and the changes that occur are minimal $[11,12]$. Intestinal decontamination with rifaximin is an attractive approach in the treatment of patients with cirrhosis with SBP.

The emergence of resistant bacteria creates challenges in SBP treatment. Therefore, new classes of antibiotics or antibiotic combination need to be developed.

The aim of the study was assessing the effect of adding rifaximin to cefotaxime in treatment of SBP compared with the use of cefotaxime alone.

\section{Materials and methods}

The study was a prospective randomized single-blinded study that was conducted in Sohag University Hospital, Faculty of Medicine, Sohag University, during the period from July 2016 to July 2017. The study included patients with cirrhosis with SBP, aged greater than 18 years, who accepted participation in this study. It was performed in accordance with the principles of the Declaration of Helsinki. The exclusion criteria included presence of hepatocelluar carcinoma greater than or equal to $3 \mathrm{~cm}$, hepatic encephalopathy grade II or more, gastrointestinal tract bleeding in the last 4 weeks, presence of renal impairment with serum creatinine greater than $3 \mathrm{mg} /$ $\mathrm{dl}$, history of allergy to cefotaxime or rifaximin or associated infection that was in need for particular antibiotic therapy. Patients on secondary prophylaxis for SBP or receiving antibiotic in the last $72 \mathrm{~h}$ before admission were not included. Diagnosis of liver cirrhosis was based upon clinical evaluation, liver function tests, abdominal ultrasonography, and hepatitis markers or PCR. Diagnosis of SBP was done according to international guidelines if the polymorphonuclear leukocyte (PMN) cell count in the ascetic fluid exceeded $250 / \mathrm{ml}$ in the absence of source of intraabdominal infection [13].

Clinical evaluation for all patients was done, including full history, clinical examination, and investigations that included liver and renal function tests, complete blood picture, and coagulation profile. Diagnostic aspiration of the ascetic fluid was conducted in all admitted patients with cirrhosis with ascites at the time of admission. The included patients with SBP were randomly divided to two groups. Each group included equal number of patients. Patients in group I received cefotaxime $4 \mathrm{~g} /$ day intravenously in two divided doses for 5 days, whereas patients in group II received combination of cefotaxime $4 \mathrm{~g} /$ day intravenously in two divided doses and rifaximin $800 \mathrm{mg} /$ day orally in two divided doses for 5 days. Each patient assigned a written informed consent, and the study protocol was approved from our university ethics committee. The included patients underwent repeated diagnostic aspiration and blood sample for white blood cells (WBCs) count and serum creatinine on the third day of antibiotic therapy.

\section{Statistical analysis}

Mean, SD, median, and range were obtained for the quantitative data. Means of two groups were compared using Student's $t$-test. Mann-Whitney test was used to compare two groups with data not normally distributed. $\chi^{2}$-test was used for qualitative data. $P$ value was considered significant if it was less than 0.05. The data were analyzed using statistical package for the social sciences version 16.0 for Windows (SPSS; SPSS Inc., Chicago, Illinois, USA).

\section{Results}

\section{Clinical characteristic of the patients}

The study involved 98 patients with cirrhosis with SBP. It included 51 (52.04\%) male and 47 (47.96\%) female, with mean age of $58.01 \pm 9.74$ years and range 18-76 years. The etiology of liver cirrhosis was hepatitis B virus (HBV) in $13(13.26 \%)$ patients, hepatitis $\mathrm{C}$ virus (HCV) in 75 (76.53\%) patients, and both $\mathrm{HCV}$ and $\mathrm{HBV}$ in one (1.02\%) patient. The remaining nine $(9.18 \%)$ patients were negative for HCV and HBV. Child-Pugh score was Child B in 46 (46.94\%) patients and Child C in 52 (53.06\%) patients. Model for end-stage liver disease (MELD score) mean was $20.07 \pm 7.20$ and range was $7-40$. A total of $53(54.08 \%)$ patients were presented by fever, and $43(43.88 \%)$ were presented by abdominal pain. The baseline clinical and laboratory data of the patients are shown in Table 1.

\section{Clinical characteristic of group I and group II}

Group I included 49 (50\%) patients with cirrhosis with SBP who received cefotaxime alone., Their mean age was $57.96 \pm 9.97$ year, and $24(48.97 \%)$ patients were females. Group II included 49 (50\%) patients, with 
Table 1 Clinical and laboratory data of the 98 included patients

\begin{tabular}{|c|c|}
\hline Variables & Summary statistics \\
\hline \multicolumn{2}{|l|}{ Age } \\
\hline Mean $\pm S D / m e d i a n$ (range) & $58.01 \pm 9.74 / 58(18-76)$ \\
\hline \multicolumn{2}{|l|}{$\operatorname{Sex}[n(\%)]$} \\
\hline Females/males & $47(47.96) / 51(52.04)$ \\
\hline \multicolumn{2}{|l|}{ Cause of liver cirrhosis $[n(\%)]$} \\
\hline $\mathrm{HBV} / \mathrm{HCV}$ & $13(13.26) / 75(76.53)$ \\
\hline $\mathrm{HBV}$ and $\mathrm{HCV} /$ others & $1(1.02) / 9(9.18)$ \\
\hline \multicolumn{2}{|l|}{ Child-Pugh score $[n(\%)]$} \\
\hline Child B/Child C & $46(46.94) / 52(53.06)$ \\
\hline \multicolumn{2}{|l|}{ MELD score } \\
\hline Mean $\pm \mathrm{SD} /$ median (range) & $20.07 \pm 7.20 / 19(7-40)$ \\
\hline \multicolumn{2}{|l|}{ Fever $[n(\%)]$} \\
\hline No/yes & $45(45.92) / 53(54.08)$ \\
\hline \multicolumn{2}{|l|}{ Abdominal pain $[n(\%)]$} \\
\hline No/yes & $55(56.12) / 43(43.88)$ \\
\hline \multicolumn{2}{|l|}{ WBCs $\left(\times 10^{9} / \mathrm{I}\right)$} \\
\hline Mean $\pm S D / m e d i a n$ (range) & $13.45 \pm 1.39 / 13(10.5-17)$ \\
\hline \multicolumn{2}{|l|}{ Hemoglobin (g/dl) } \\
\hline Mean $\pm \mathrm{SD} /$ median (range) & $9.08 \pm 2.26 / 9(3-14.6)$ \\
\hline \multicolumn{2}{|l|}{ Platelet count $\left(\times 10^{9} / I\right)$} \\
\hline Mean $\pm \mathrm{SD} /$ median (range) & $112.56 \pm 74.71 / 92(20-435)$ \\
\hline \multicolumn{2}{|l|}{ ALT (IU/I) } \\
\hline Mean $\pm \mathrm{SD} /$ median (range) & $48.86 \pm 68.06 / 35(3-847)$ \\
\hline \multicolumn{2}{|l|}{ Serum albumin (g/dl) } \\
\hline Mean $\pm \mathrm{SD} /$ median (range) & $2.09 \pm 0.53 / 2.0(0.8-3.2)$ \\
\hline \multicolumn{2}{|l|}{ Direct bilirubin (mg/dl) } \\
\hline Mean $\pm \mathrm{SD} /$ median (range) & $2.71 \pm 2.45 / 2(0.1-21.04)$ \\
\hline \multicolumn{2}{|l|}{ Serum creatinine $(\mathrm{mg} / \mathrm{dl})$} \\
\hline Mean $\pm \mathrm{SD} /$ median (range) & $2.00 \pm 0.25 / 2.0(1.4-2.7)$ \\
\hline \multicolumn{2}{|l|}{ INR } \\
\hline Mean $\pm \mathrm{SD} /$ median (range) & $1.76 \pm 0.71 / 1.55(0.97-4.98)$ \\
\hline \multicolumn{2}{|l|}{ PMN in ascetic fluid (cells $/ \mathrm{mm}^{3}$ ) } \\
\hline Mean $\pm \mathrm{SD} /$ median (range) & $1526.98 \pm 1463.43 / 537(269-5576)$ \\
\hline
\end{tabular}

mean age of $58.07 \pm 9.54$ years, and $26(53.06 \%)$ patients were male. The etiology of liver cirrhosis in group I was $\mathrm{HBV}$ in six (12.24\%) patients, $\mathrm{HCV}$ in 37 (75.51\%) patients, both $\mathrm{HCV}$ and $\mathrm{HBV}$ in one (2.04\%) patient and other causes in five (10.2\%) patients. Group II showed HBV in seven (14.28\%) patients, $\mathrm{HCV}$ in $38(77.55 \%)$ patients, and other causes in four $(8.16 \%)$ patients. No included patients in group II had combined HCV and HBV infection. Overall, 27 (55.1\%) patients in group I were Child C and $22(44.89 \%)$ were Child B, and their mean MELD score was 19.69 \pm 7.04 . Group II included 25 (61.02\%) patients with Child $\mathrm{C}$ and 24 (48.98\%) patients with Child B, and their mean MELD score was 20.46 \pm 7.17 . There was no significant differences between group I and group II regarding age, sex, causes of liver cirrhosis, Child score, or MELD score, as shown in Table 2.
Laboratory data of group I and group II on the first and thirdrd day

WBC count was $13.45 \pm 1.35$ and $11.62 \pm 0.64$ on the first and third day, respectively, in group I, whereas it was $13.57 \pm 1.39$ and $9.73 \pm 2.73$ on the first and third day, respectively, in group II. Both groups showed significant reduction in $\mathrm{WBC}$ on the third day compared with the first day, with $P$ value less than 0.0001. Moreover, group II showed significant reduction in $\mathrm{WBC}$ on the third day compared with the reduction in group I, with $P$ value less than 0.0001 . PMN count in ascetic fluid in group I was 1526.98 \pm 1463.4 on the first day, and it was $930.2 \pm 786.89$ on the third day of therapy. Reduction in the PMN count was statistically significant with $P$ value less than 0.0001. Group II also showed significant reduction in the PMN count on the third day, with $P$ value less than 0.0001. Moreover, reduction in PMN count in the third day in group II, compared with group I, was statistically significant, with $P$ value less than 0.0001 . Similar changes were detected in both groups in serum creatinine. Both groups showed significant reduction on the third day compared with the first day, and the reduction was statistically significant in group II compared with group I, as shown in Table 3.

\section{Discussion}

SBP is a dangerous complication of advanced liver disease. High prevalence of small intestinal bacterial overgrowth was reported among patients with cirrhosis [1], and it has been associated with the development of SBP because of the bacterial translocation from the intestine to the systemic circulation, and also to the ascetic fluid [14]. According to Child-Pugh score, the studied patients included 46 patients with Child B and 52 with Child C. The composition of ascetic bacteria is correlated with the stage of liver decompensation and the Child-Pugh score. The link proves the relation between gut microbiota and the progression of cirrhosis [15]. Therefore, it has been assumed that rifaximin, being appropriate in small intestine bacterial overgrowth therapy, could be useful in prevention and treatment of SBP.

In the present study, 49 patients were included in each treated group. The third-generation cephalosporin for 5 days is the conventional treatment for SBP [13]. However, its efficacy was reduced owing to the rise in bacterial resistance. In addition, its use became unsuitable for enterococci, which have become more frequent cause in SBP [16]. Bad outcome upon survival is strongly associated with failure of first-line therapy [17]. 
Table 2 Comparison of clinical and laboratory data between group I and group II

\begin{tabular}{|c|c|c|c|}
\hline Variables & Group I $(N=49)(50 \%)$ & Group II $(N=49)(50 \%)$ & $P$ value \\
\hline \multicolumn{4}{|l|}{ Age } \\
\hline Mean $\pm S D / m e d i a n$ (range) & $57.96 \pm 9.96 / 58(25-76)$ & $58.07 \pm 9.54 / 58(18-75)$ & 0.93 \\
\hline \multicolumn{4}{|l|}{$\operatorname{Sex}[n(\%)]$} \\
\hline Females/males & $24(48.97) / 25(51.02)$ & $23(46.94) / 26(53.06)$ & 0.94 \\
\hline \multicolumn{4}{|l|}{ Cause of liver cirrhosis $[n(\%)]$} \\
\hline $\mathrm{HBV} / \mathrm{HCV}$ & $6(12.24) / 37(75.51)$ & $7(14.28) / 38(77.55)$ & 0.54 \\
\hline $\mathrm{HBV}$ and $\mathrm{HCV} /$ others & $1(2.04) / 5(10.2)$ & $0 / 4(8.16)$ & \\
\hline \multicolumn{4}{|l|}{ Child-Pugh score $[n(\%)]$} \\
\hline Child B/Child C & $22(44.89) / 27(55.1)$ & $24(48.98) / 25(61.02)$ & 0.77 \\
\hline \multicolumn{4}{|l|}{ MELD score } \\
\hline Mean $\pm \mathrm{SD} /$ median (range) & $19.69 \pm 7.04 / 19(7-36)$ & $20.46 \pm 7.17 / 19(7-40)$ & 0.47 \\
\hline \multicolumn{4}{|l|}{ Fever $[n(\%)]$} \\
\hline No/yes & $21(42.9) / 28(57.14)$ & $24(48.98) / 25(51.02)$ & 0.51 \\
\hline \multicolumn{4}{|l|}{ Abdominal pain $[n(\%)]$} \\
\hline No/yes & $27(55.1) / 22(44.89)$ & $28(57.14) / 21(42.86)$ & 0.09 \\
\hline \multicolumn{4}{|l|}{ Hemoglobin (g/dl) } \\
\hline Mean $\pm S D / m e d i a n$ (range) & $9.02 \pm 2.15 / 9(3.6-14)$ & $9.15 \pm 2.38 / 9.5(3-14.6)$ & 0.59 \\
\hline \multicolumn{4}{|l|}{ Platelet count $\left(\times 10^{9} / \mathrm{l}\right)$} \\
\hline Mean $\pm S D / m e d i a n$ (range) & $105.82 \pm 59.5 / 91(33-405)$ & $120.15 \pm 88.4 / 93(20-435)$ & 0.59 \\
\hline \multicolumn{4}{|l|}{ ALT (IU/I) } \\
\hline Mean \pm SD/median (range) & $57.85 \pm 86.91 / 40(3-847)$ & $38.75 \pm 34.33 / 30$ (9-292) & 0.0006 \\
\hline \multicolumn{4}{|l|}{ Albumin (g/dl) } \\
\hline Mean \pm SD/median (range) & $2.03 \pm 0.48 / 2(1-3.2)$ & $2.17 \pm 0.58 / 2(0.8-3.1)$ & 0.08 \\
\hline \multicolumn{4}{|l|}{ Direct bilirubin (mg/dl) } \\
\hline Mean $\pm \mathrm{SD} /$ median (range) & $2.85 \pm 2.71 / 2(0.1-21.4)$ & $2.56 \pm 2.10 / 2(0.1-17.4)$ & 0.98 \\
\hline \multicolumn{4}{|l|}{ INR } \\
\hline Mean \pm SD/median (range) & $1.61 \pm 0.41 / 1.5(0.97-3.49)$ & $1.92 \pm 0.91 / 1.62(1-4.98)$ & 0.0002 \\
\hline
\end{tabular}

ALT, alanine aminotransferase; HBV, hepatitis B virus; HCV, hepatitis C virus; INR, international normalized ratio; MELD, model for endstage liver disease; PMN, polymorphonuclear leukocyte cell count. WBCs, white blood cells count.

Table 3 Comparison of laboratory data in group I and group II between the first and the third day

\begin{tabular}{|c|c|c|c|}
\hline Variables & Group I & Group II & $P$ value \\
\hline \multicolumn{4}{|l|}{ WBCs at first day } \\
\hline Mean $\pm \mathrm{SD} /$ median (range) & $13.45 \pm 1.35 / 13(11.5-16)$ & $13.57 \pm 1.39 / 13.5(10.5-17)$ & 0.41 \\
\hline \multicolumn{4}{|l|}{ WBCs at third day } \\
\hline Mean $\pm \mathrm{SD} /$ median (range) & $11.62 \pm 0.64 / 11.5(10-12.5)$ & $9.73 \pm 2.73 / 10(4-13)$ & $<0.0001$ \\
\hline$P$ value & $<0.0001$ & $<0.0001$ & \\
\hline \multicolumn{4}{|l|}{ PMN at first day } \\
\hline Mean \pm SD median (range) & $1526.98 \pm 1463.4 / 537(269-5576)$ & $1535.2 \pm 1577.6 / 525(264-5571)$ & 0.06 \\
\hline \multicolumn{4}{|l|}{ PMN at third day } \\
\hline Mean $\pm \mathrm{SD} /$ median (range) & $930.2 \pm 786.89 / 430(123-2309)$ & $837.6 \pm 1442.08 / 260(108-5067)$ & $<0.0001$ \\
\hline$P$ value & $<0.0001$ & $<0.0001$ & \\
\hline \multicolumn{4}{|l|}{ Creatinine on the first day } \\
\hline Mean $\pm \mathrm{SD} /$ median (range) & $2.09 \pm 0.25 / 2.0(1.6-2.6)$ & $2.00 \pm 0.24 / 1.9(1.4-2.7)$ & 0.8 \\
\hline \multicolumn{4}{|l|}{ Creatinine on the third day } \\
\hline Mean $\pm \mathrm{SD} /$ median (range) & $1.61 \pm 0.19 / 1.6(1.1-1.8)$ & $1.28 \pm 0.37 / 1.15(0.9-2.0)$ & $<0.0001$ \\
\hline$P$ value & $<0.0001$ & $<0.0001$ & \\
\hline
\end{tabular}

PMN, polymorphonuclear leukocyte cell count in ascetic fluid; WBCs, white blood cells count.

Combinations of recent broad-spectrum antibiotics like glycopeptides and carbapenems were considered as effective alternative therapy, and this was based on isolates from culture-positive SBP [18,19]. The benefit of combination therapy in treatment of SBP has been reported [20]. However, this was faced by high costs, their toxicity, and fears about emergence of more multiresistant microorganisms. Therefore, it is important to identify the pathogenesis of SBP and the role of gut microbiota to select patients who are expected to get benefit from broader antibiotic treatment or antibiotic combination.

In our study, the use of rifaximin at the dose of $800 \mathrm{mg} /$ day orally was based on the previous reports postulating 
that the uptake of $800-\mathrm{mg}$ rifaximin for 5 days markedly reduces fecal Escherichia coli population, and the fact that $E$. coli is the most commonly isolated microorganisms from cases of SBP [21,22].

We detected significant reduction in the WBCs count after 3 days of antibiotic therapy in both treated groups. Moreover, patients with cirrhosis in rifaximin group showed more significant reduction in WBC count compared with those received cefotaxime alone. This significant reduction in WBC could refer to more beneficial effect of combination therapy by adding rifaximin over cefotaxime alone in treatment of SBP. Combination of systemic and local antibiotic may be more effective therapy than either alone through counteracting the enteric microorganisms' migration to the systemic circulation and ascetic fluid through the intestinal wall.

Our study showed significant reduction in the ascetic fluid PMN count after 3 days of antibiotic therapy in both groups. Patients with cirrhosis receiving rifaximin and cefotaxime showed more significant reduction in ascetic fluid neutrophil count compared with those receiving cefotaxime alone. The positive effect of adding rifaximin could be owing to reduction of bacterial translocation from the small intestine to the ascetic fluid and the possible immunomodulatory effect of rifaximin. Selective intestinal decontamination, used in secondary prophylaxis of SBP, modulates patients' proinflammatory reaction $[23,24]$. However, the immunomodulatory effect of rifaximin was observed after several weeks of its use in secondary prophylaxis of SBP $[23,24]$, and there are no data about this effect after few days of treatment.

Significant reduction in serum creatinine after 3 days of antibiotic treatment was detected in both studied group. This reduction was more significant among patients with cirrhosis in rifaximin group than those who received cefotaxime alone. In patients with cirrhosis with SBP, antibiotic treatment as well as prevention of renal failure are important prognostic factors for reduction of mortality $[25,26]$. Significant improvement in renal function in both groups refers to the importance of early and proper initiation of antibiotic therapy in SBP to prevent deterioration of renal function and development of hepatorenal syndrome. Adding rifaximin in combination therapy carries the advantage of being nonabsorbable and lacking restriction for use in presence of impaired renal function. Kalambokis et al. [23] reported improvement in systemic hemodynamics and renal function that is achieved by intestinal decontamination with rifaximin for 4 weeks in patients with advanced cirrhosis. However, systemic hemodynamic effects of rifaximin after few days need an evaluation and could not be equal to 4 weeks of therapy. Substitution of albumin should be considered, and this play an important role in prevention of hepatorenal syndrome [27].

We faced some limitations in this study. First, the lack of assessment of the effect of adding rifaximin therapy in SBP on hepatic encephalopathy and mortality. Second, lack of measurement of the immunomodulatory effects of rifaximin during treatment of SBP. Lastly, lack of follow-up of recurrence of SBP among the treated patients. However, our study is the first study that refers to rifaximin use in treatment of SBP rather than its use in preventing SBP. Considering the role of enteric flora in the pathophysiology of SBP has expanded the choice of rifaximin in prevention and treatment of SBP and opens the door to the use of combination therapy in such serious complication.

We concluded that rifaximin plus cefotaxime showed some favorable effects in treatment of SBP than cefotaxime alone. However, the clinical effects and potential role of rifaximin and combination therapy in management of SBP need to be clarified in further studies.

\section{Financial support and sponsorship} Nil.

\section{Conflicts of interest}

There are no conflicts of interest.

\section{References}

1 Giannelli V, Di Gregorio V, lebba V, Giusto M, Schippa S, Merli M, Thalheimer U. Microbiota and the gut-liver axis: bacterial translocation, inflammation and infection in cirrhosis. World J Gastroenterol 2014; 20:16795.

2 Nousbaum JB, Cadranel JF, Nahon P, Khac EN, Moreau R, Thévenot T, et al. Diagnostic accuracy of the Multistix 8 SG reagent strip in diagnosis of spontaneous bacterial peritonitis. Hepatology 2007; 45:1275-1281.

3 Chang CS, Chen GH, Lien HC, Yeh HZ. Small intestine dysmotility and bacterial overgrowth in cirrhotic patients with spontaneous bacterial peritonitis. Hepatology 1998; 28:1187-1190.

4 Guarner C, Runyon BA, Young S, Heck M, Sheikh MY. Intestinal bacterial overgrowth and bacterial translocation in cirrhotic rats with ascites. J Hepatol 1997; 26:1372-1378.

5 Bonnel AR, Bunchorntavakul C, Reddy KR. Immune dysfunction and infections in patients with cirrhosis. Clin Gastroenterol Hepatol 2011; 9:727-738.

6 Rimola A, Salmerón JM, Clemente G, Rodrigo L, Obrador A, Miranda ML, et al. Two different dosages of cefotaxime in the treatment of spontaneous bacterial peritonitis in cirrhosis: results of a prospective, randomized, multicenter study. Hepatology 1995; 21:674-679.

7 Biecker E. Diagnosis and therapy of ascites in liver cirrhosis. World J Gastroenterol 2011; 17:1237.

$8 \mathrm{Koo} \mathrm{HL}$, DuPont HL. Rifaximin: a unique gastrointestinal-selective antibiotic for enteric diseases. Curr Opin Gastroenterol 2010; 26:17. 
9 De Leo C, Eftimiadi C, Schito G. Rapid disappearance from the intestina tract of bacteria resistant to rifaximin. Drugs Exp Clin Res 1986; 12:979-981.

10 Debbia E, Maioli E, Roveta S, Marchese A. Effects of rifaximin on bacterial virulence mechanisms at supra-and sub-inhibitory concentrations. J Chemother 2008; 20:186-194

11 Brigidi P, Swennen E, Rizzello F, Bozzolasco M, Matteuzzi D. Effects of rifaximin administration on the intestinal microbiota in patients with ulcerative colitis. J Chemother 2002; 14:290-295.

12 Xu D, Gao J, Gillilland M, Wu X, Song I, Kao JY, Owyang C. Rifaximin alters intestinal bacteria and prevents stress-induced gut inflammation and visceral hyperalgesia in rats. Gastroenterology 2014; 146:484-496.

13 Ginés $\mathrm{P}$, Angeli $\mathrm{P}$, Lenz K, Møller S, Moore K, Moreau R. European Association for the Study of the Liver. EASL clinical practice guidelines on the management of ascites, spontaneous bacterial peritonitis, and hepatorenal syndrome in cirrhosis. J Hepatol 2010; 53:397-417.

14 Hanouneh MA, Hanouneh IA, Hashash JG, Law R, Esfeh JM, Lopez R, etal. The role of rifaximin in the primary prophylaxis of spontaneous bacterial peritonitis in patients with liver cirrhosis. J Clin Gastroenterol 2012; 46:709-715.

15 Rogers GB, van der Gast CJ, Bruce KD, Marsh P, Collins JE, Sutton J, Wright M. Ascitic microbiota composition is correlated with clinical severity in cirrhosis with portal hypertension. PLoS One 2013; 8:e74884.

16 Reuken P, Pletz M, Baier M, Pfister W, Stallmach A, Bruns T. Emergence of spontaneous bacterial peritonitis due to enterococci-risk factors and outcome in a 12-year retrospective study. Aliment Pharmacol Ther 2012; 35:1199-1208.

17 Umgelter A, Reindl W, Miedaner M, Schmid R, Huber W. Failure of current antibiotic first-line regimens and mortality in hospitalized patients with spontaneous bacterial peritonitis. Infection 2009; 37:2-8.

18 Jalan R, Fernandez J, Wiest R, Schnabl B, Moreau R, Angeli P, et al. Bacterial infections in cirrhosis: a position statement based on the EASL Special Conference 2013. J Hepatol 2014; 60:1310-1324.
19 Fernández J, Gustot T. Management of bacterial infections in cirrhosis. J Hepatol 2012; 56:S1-S12.

20 Piano S, Salinas F, Morando F, Cavalin M, Romano A, Rosi S, et al. Poster Session 1: infections and acute on chronic liver failure. Abstract 574: the empirical antibiotic treatment of nosocomial spontaneous bacterial peritonitis in patients with decompensated liver cirrhosis: results of a randomized controlled clinical trial. Hepatology 2014; 60:478A-501A

21 Zullo A, Hassan C, Ridola L, Lorenzetti R, Campo SM, Riggio O. Rifaximin therapy and hepatic encephalopathy: pros and cons. World J Gastrointest Pharmacol Ther 2012; 3:62.

22 Koulaouzidis A, Bhat S, Karagiannidis A, Tan W, Linaker B. Spontaneous bacterial peritonitis. Postgrad Med J 2007; 83:379-383.

23 Kalambokis GN, Mouzaki A, Rodi M, Pappas K, Fotopoulos A, Xourgia X Tsianos EV. Rifaximin improves systemic hemodynamics and renal function in patients with alcohol-related cirrhosis and ascites. Clin Gastroenterol Hepatol 2012; 10:815-818.

24 Zapater P, Caño R, Llanos L, Ruiz-Alcaraz AJ, Pascual S, Barquero C, et al. Norfloxacin modulates the inflammatory response and directly affects neutrophils in patients with decompensated cirrhosis. Gastroenterology 2009; 137:1669-1679.

25 Tandon P, Garcia-Tsao G. Renal dysfunction is the most important independent predictor of mortality in cirrhotic patients with spontaneous bacterial peritonitis. Clin Gastroenterol Hepatol 2011; 9:260-265.

26 Wong F, O'Leary JG, Reddy KR, Patton H, Kamath PS, Fallon MB, et al. New consensus definition of acute kidney injury accurately predicts 30-day mortality in patients with cirrhosis and infection. Gastroenterology 2013; 145:1280-1288.

27 Runyon BA, Borzio M, Young S, Squier SU, Guarner C, Runyon MA. Effect of selective bowel decontamination with norfloxacin on spontaneous bacterial peritonitis, translocation, and survival in an animal model of cirrhosis. Hepatology 1995; 21:1719. 